\title{
What do early childhood teacher graduands say about working with infants and toddlers?: An exploratory investigation of perceptions
}

\author{
Susanne Garvis \\ University of Gothenburg
}

\author{
Donna Pendergast \\ Griffith University
}

\begin{abstract}
RECENT INITIATIVES IN THE early childhood education and care sector have increased the demand for early childhood teachers to work in long day care settings. This study explores the perceptions of pre-service teachers who had recently finished their final semester of study and were due to graduate from one Australian higher education institution in the state of Queensland. A cohort of pre-service teachers was invited to complete an online survey investigating their perceptions of working with infants and toddlers. A response rate of 80 per cent, representing 25 respondents, participated in the study. Descriptive statistics and content analysis were employed to analyse the survey data. The findings reveal that overall, pre-service teachers reported they had a partial knowledge of children aged birth to three years after completion of their teacher education program. This was despite 10 days of placement with infants and toddlers, and knowledge and content about infants and toddlers being embedded throughout the teacher education program (birth to eight years). Findings are also relevant to industry and government policy-makers who are advocating for qualified early childhood teachers to work in prior to formal school settings within Australia.
\end{abstract}

\section{Introduction}

Early childhood teacher education within Australia is a complex arena. A variety of teacher education programs have been approved by the Australian Children's Education and Care Quality Authority (ACECOA). Some approved programs focus on children aged birth to five years, and others on birth to eight years. Variation may also occur in course structure and professional experience. For example, some universities may embed knowledge on infants and toddlers across their subjects, while others may have subjects specifically focused on infants and toddlers. Variation can also occur regarding the number of professional experience days, with some programs offering those mandated by ACECQA, and others many more. Such variation is likely to result in differences in the capacities of graduates across the country. Research is thus needed into outcomes for graduates from these programs, including their own perceptions of their competence.

This study takes the stance that a theoretically rich understanding of teaching and learning is important for ensuring quality in early childhood education (ECE). This understanding grows when students study early childhood teaching and learning. In ECE this includes a focus on children from birth to five years.
Recent research on early childhood teacher education programs within Australia suggest some universities may focus less on infants and toddlers and more on children aged three and above (Garvis, Lemon, Pendergast \& Yim, 2013). There is a need within Australian early childhood teacher education research to explore this finding and examine the perceptions of graduates about working with the youngest of children.

This study reports on the findings of a survey administered to 25 pre-service teachers at one institution in Queensland, Australia who were at the end of their undergraduate program of study and about to graduate and enter the teaching profession. The pre-service teachers were enrolled in a Bachelor of Primary Education (early childhood specialisation birth to eight years) that would allow them to be employed in either prior to formal school settings (such as long day care) or in a preschool.

The online survey was designed to capture the graduating teachers' perceptions about working with infants and toddlers. Learning about infants and toddlers had been embedded in their teacher education program. The graduating teachers had also undertaken a 10-day placement working with children aged birth to two years during their teacher education program. They had also undertaken professional experience in kindergarten and a primary school. 


\section{Literature review}

In Australian early childhood education and care, the National Quality Framework for Early Childhood Education and Care (COAG, 2009) has been developed to raise quality and drive continuous improvement across all early childhood education and care services. The framework mandates that all childcare programs are to employ a four-year degree qualified early childhood teacher. In Queensland the guidelines require (Queensland Government Office for Early Childhood Education and Care, 2013):

From 1 January 2014, all centre-based services with children under school age (primarily long day care and kindergarten services) will need to have access to a qualified early childhood teacher or have one in attendance at the service (p. 3).

Growing evidence from a range of research studies reveals that when early childhood educators hold higher levels of qualifications, there is a better chance of quality programs for children (Sylva, Melhuish, Sammons, Siraj-Blatchford \& Taggart, 2011). The evidence suggests that early childhood teachers with higher-level qualifications are more likely to engage in appropriate interactions that are sensitive, responsive and engaged (Norris, 2010). Higher qualified early childhood teachers have also been linked to greater staff-initiated learning, and to staff being more engaged in play and social interactions with children (Dowling \& O'Malley, 2009; Mitchell, 2010), particularly for infants and toddlers (Hannon, 2003; Ireland, 2006). Thus, there is an expectation underpinning the framework that highly qualified early childhood teachers will make a positive difference to service quality, providing better outcomes for children (Nolan \& Rouse, 2013).

In Australia, the age range birth to three years has received scant attention in many early childhood teacher education programs (Garvis et al., 2013). Garvis and colleagues (2013) found that many programs appeared to spend more time on older children, with few assessment items dedicated specifically to infants and toddlers. Garvis et al. (2013, p. 14) argued:

[I]f there is to be an improvement in the quality of early childhood education and care, it is important that preservice teachers are provided with adequate knowledge and experience to understand the importance of infants and toddlers.

Findings are similar in the United States. Although most early childhood teacher education programs claim to have a broad reach across the range of children from birth to eight years, typically there is only a light touch in the earliest years (Recchia \& Shin, 2010). Recchia and Shin (2010) also suggest this may be because there is a perception in the United States that the educational preparation required of infant and toddler 'caregivers' is less rigorous than that required of 'teachers' of older children.
There is also some evidence in Australia that pre-service early childhood teachers want to work with older children as opposed to younger children within early childhood settings (Nolan \& Rouse, 2013). This preference may reflect the low professional status of teachers working in child care, along with salary and other industrial conditions, when compared with school employment. The professional status of teachers in childcare settings is not comparable to that of teachers in school settings, with a widespread perception that teachers in child care are not 'real' teachers (Ali, 2009; Sumsion, 2007), and they do not share the same professional status as teachers in other education settings (de Leon-Carillo, 2007).

In another Australian study, Thorpe, Ailwood, Brownlee and Boyd (2011) explored the beliefs of pre-service teachers in their third year of study of a Bachelor of Education (early childhood specialisation). The study found that while pay, conditions and status of early childhood teachers act as barriers to working in the childcare sector, over half the students said they would consider working in this sector. Students who had a positive practical experience were found to be more likely to consider entering the childcare workforce. The different findings from the Australian literature suggest possible differences in preservice teacher perceptions between primary programs with early childhood specialisations and early childhood programs. The study will explore this further by focusing on a primary program that has an early childhood specialisation.

\section{Context}

At the university where the present study took place, an early childhood specialisation (birth to eight years) was embedded in the Bachelor of Education (Primary). The pre-service teachers involved in this study were in the final year of a fouryear Bachelor of Education (Primary) program in Queensland. It was designed to prepare pre-service teachers to work in prior to formal school settings as well as in primary school (up to eight years of age). The program was also approved by the Queensland College of Teachers (OCT) which is the registering authority to whom graduating teachers apply for provisional registration. The program was revised in early 2011 to meet the requirements for early childhood placements. This revision included the introduction of an infant and toddler placement.

Within the program, students were expected to undertake 80 days of professional experience as part of the early childhood specialisation. This consisted of 10 days of placement with infants and toddlers, 40 days with children aged two to five years and the remaining 30 days with children aged five to eight years.

\section{Method}

This study is located in the interpretivist paradigm (Cohen, Manion \& Morrison, 2000). An interpretivist approach can facilitate insights into emotions, meaning and reasons 
for actions. As Schwandt (1994, p. 118) suggests, 'to understand the world of meaning, one must interpret it'. An interpretive approach was used for this study to explore the perceptions of graduating pre-service teachers about working with infants and toddlers.

A mixed design survey was employed that included quantitative and qualitative questions. An online survey was chosen as it allowed participants to complete the survey at a time convenient to them and away from the university campus.

Ethical approval was gained from the University Human Ethics Committee. Participants were not taught by the research team, limiting coercion and power dimensions. Once ethical approval was obtained, the pre-service teachers were sent an email advertising the research project. A convenience sample was chosen because of ease of access. The email included a link to the online survey questions hosted by SurveyMonkey. Pre-service teachers could choose to voluntarily participate by clicking the link, or could choose not to participate by deleting the invitational email. Two reminder emails were sent to all students approximately one week after the initial invitation email was sent. Pre-service teachers were then given an additional three weeks to complete the survey. The survey was anonymous and participants did not provide their contact details or other identifiers.

The timing of the online survey was crucial to elicit a high response rate. Previous online surveys in Australia with preservice generalist teachers had low response rates of 14 per cent (O'Neill \& Stephenson, 2012). Sax, Gilmartin and Bryant (2003) suggest low response rates with university students as respondents could be due to being bombarded by questionnaires, a lack of time to participate in voluntary activities and a perceived lack of relevance. The survey in this study was sent after all university surveys and assessment work had finished for the semester. The survey achieved a response rate of 80 per cent, with 25 out of 31 students all providing complete responses. Participants were all female and aged between 22 and 36 years.

The participants had completed 10 days of professional experience with infants and toddlers. The design of the Bachelor program did not have a specific subject focused on infants and toddlers. Rather, learning about infants and toddlers was embedded across all of the subjects.

An online survey was created based on a combination of closed and open questions and consisted of five main questions. The survey focused on perceptions of working with this age range and also current knowledge of working with infants and toddlers. The pre-service teachers were asked to rate their current level of knowledge and understanding about children birth to three years. An example of a research question was:

\section{How would you rate your current knowledge and} understanding of children birth to three years?
Pre-service teachers were also asked to comment on their emotional state if they were offered a position working with children birth to three years. Participants were given a range of emotions to choose from and could also add their own (see Table 1). Emotional response scales have been used in studies relating to experience and response to stimuli (Fink, 2003). The emotional response for this question was related to the stimuli about working with infants and toddlers. The intention was to find emotional experiences that influence competence and confidence for teachers.

The survey was piloted with a third year cohort of preservice teachers for readability and in order to establish the duration of time required to complete the survey. The third year pre-service teachers were asked to read the survey and comment on any wording they did not understand. They were also asked to record the time it took to complete the survey.

The quantitative sections of the survey used with graduands were analysed using basic descriptive statistics (mean and frequency counts) to determine the most common responses. Since the cohort was small, it was impossible to move beyond descriptive statistics. Extended response questions (qualitative data) were analysed using content analysis, 'a research technique for making replicable and valid inferences from texts [or other meaningful matter] to the context of their use' (Krippendorff, 2004, p. 18). Coding for manifest content (Wallen \& Fraenkel, 2001) was used as the basis of the analysis, meaning that the written words were interpreted literally.

It is important to point out the limitations of this study. Although the study achieved a high response rate, the population under investigation was small. In addition, just one cohort of students in one program specialisation at one university was invited to participate. So, although the findings provided some direction, they cannot be generalised to all Australian pre-service early childhood student teachers.

Another limitation relates to the trustworthiness of the selfreported data. Participants may have had inaccurate recall (Stough, 2006), under- or over-estimatinig their capabilities. Like all self-report studies, the perceptions were those as reported, and may not reflect the reality of the situation being investigated.

Findings are presented within three themes.

\section{Findings}

\section{Current perceived knowledge and understanding about children aged birth to three years}

The pre-service teachers were asked to rank their current knowledge and understanding of children birth to three years on a five-point Likert scale. The rankings were: nil knowledge, minimal knowledge, partial knowledge, basic 
Figure 1. Pre-service teacher current ranking of knowledge and understanding

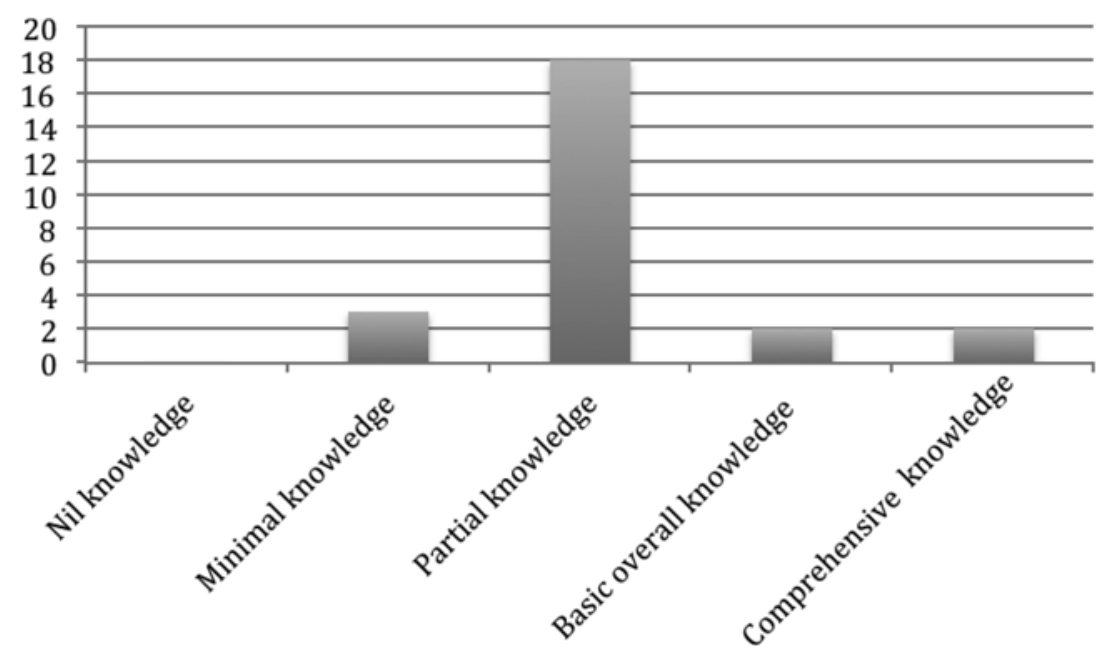

overall knowledge of key concepts and comprehensive knowledge. All participants responded that they had some knowledge of children aged birth to three years, with no participants selecting the 'nil knowledge' box (see Figure 1).

The majority of participants $(n=18$ ) responded that they had partial knowledge and understanding of children birth to three years. This was followed by minimal knowledge $(n=3)$, basic overall knowledge $(n=2)$ and comprehensive knowledge $(n=2)$. Only two participants indicated they had comprehensive knowledge of this age range, even though all students had specialised in an approved ECE program. This finding is of interest, considering the pre-service teachers had undertaken practicum experience of 10 days with children aged birth to two years, and had gained pass grades in courses with infant and toddler content. This finding suggests that the current level of time and content given to learning about infants and toddlers within the program may be inappropriate or insufficient.

The participants were also asked to comment on the key ideas concerning child development that were needed for infants and toddlers. This question was intended to show insight into what the pre-service teachers could remember from their early childhood programs regarding this age group.

The most popular response was attachment theory ( $n=16)$, suggesting this was the most important idea related to the developmental needs of children birth to three years for participants. Other areas mentioned by the participants included developmental theories $(n=4)$, the importance of quality of care $(n=3)$, brain development $(n=1)$ and viewing infants as capable $(n=1)$.

\section{Extent to which course/program has informed graduate knowledge about children aged birth to three years}

The majority ( $n=18$ ) of the pre-service teachers stated that the early childhood specialisation in the program focused more on kindergarten and preparatory education than children aged birth to three years. Typical comments included:

We mainly focused on kindergarten and primary education (Participant 1).

We probably spent more time on 3 year olds to 8 year olds (Participant 25).

The pre-service teachers also stated that when they were in generalist education subjects, there was little acknowledgement of ECE and the role of early childhood teachers before the formal years of schooling. To some participants this provided a tension between learning about ECE and primary education:

We learnt a lot about the key developmental theories however they seemed to be parallel to primary education courses. There were different ideas on teaching, management and assessment (Participant 6).

It would have been nice to see prior to formal schooling in all the subjects that we studied. I think all students in primary education need to know where children come from. I was always explaining things to people (Participant 21).

Although the pre-service teachers suggested a greater focus was placed on children aged over three years, they also identified differences in approaches, teaching and amount of time focused on different age ranges within their generalist subjects that included early childhood and primary specialists within the program. The focus of generalist subjects would be to provide a holistic understanding of children aged birth to 12 years. The comments from the participants suggested this may not have been the case. 


\section{Accepting employment opportunities to work with children aged birth to three years}

Participants were asked a yes/no question about accepting a position of employment with children birth to three years. Only one participant answered 'yes' to accepting such a position. The remaining 24 participants indicated they would not accept a position if they were offered employment with this age range.

Just over half the participants $(n=12)$ would consider working with this age range if the pay was the same as a qualified teacher in a primary school. This is surprising considering the participants had also identified gaps in their own knowledge about infants and toddlers. Respondent comments included:

After four years of study I need to take a job that has adequate pay for my family and to help repay my study debts. Unfortunately the pay in birth to three years does not provide enough for an individual to live, let alone a family (Participant 3).

A small group of participants $(n=5)$ did not want to work with this age range as they already had a job for the following year in a primary school, or they had an identity that was more closely associated with a kindergarten and preparatory teacher. This small group of participants saw limited professional status for teachers working with children aged birth to three years. The participants also stated that if you work with children from birth to three years you are not considered a teacher. As one participant explained:

I want to work with kindergarten children, not this age range. I would also waste my training as a teacher. There are no teachers in this age range so I'm not quite sure what I would do with all of my educational training. They aren't considered teachers. Policy says they are teachers but the community says no (Participant 7).

A small group of pre-service teachers $(n=8)$ also stated they felt uncomfortable working with young children. In their opinion, working with young children required higher levels of responsibility than needed for older ones, and stated they did not know how to communicate with preverbal children. One participant, for example, commented as follows:

I don't feel comfortable working with such young children and I wouldn't like the responsibility of such young children. I also don't know how I would handle the children not being able to speak (Participant 14).

Other fears of working with young children appeared to be the tasks associated with regular nappy changes and basic routines related to handling babies. The pre-service teachers were worried they did not have the practical skills necessary for very young children's care routines. Again, this was in spite of the pre-service teachers having undertaken a 10-day placement with very young children.
Participants were also invited to tick the words they would use to describe the emotions they would feel if they were offered a position for children birth to three years. More than one response could be chosen. Participants were also given an option to list their own terms in the 'other' box but no respondents completed this box. The top four feelings were unwilling, unhappy, not confident/worried and reluctant. Only a small number of participants expressed positive feelings (two participants) about working with this age range.

Table 1. Feelings of perceived employment with children birth to three years

\begin{tabular}{|l|c|}
\hline \multicolumn{1}{|c|}{ Emotion } & Percentage (n) \\
\hline Unwilling & $64 \%(16)$ \\
\hline Unhappy & $20 \%(5)$ \\
\hline Not confident/worried & $20 \%(5)$ \\
\hline Reluctant & $16 \%(4)$ \\
\hline Reserved & $8 \%(2)$ \\
\hline Confident & $8 \%(2)$ \\
\hline Excited & $4 \%(1)$ \\
\hline Concerned & $4 \%(1)$ \\
\hline Happy & $4 \%(1)$ \\
\hline Willing & $4 \%(1)$ \\
\hline Other & $0 \%(0)$ \\
\hline Tentative & $0 \%(0)$ \\
\hline
\end{tabular}

Participants were also provided with the opportunity to explain their feelings. The comments below relate to feelings of being unwilling and are also related to the significantly reduced salary conditions:

If they paid me the same as a primary teacher I would do it. You aren't even paid three quarters. I think that providing better salaries would also improve the overall quality in the profession and for children's outcomes (Participant 2).

Until the pay and conditions are fixed I will not consider it. I feel sorry for working parents as they often do not have a choice with childcare. We need qualified staff to raise the quality in this age range but we aren't prepared to pay for it. It isn't good enough. We are a wealthy nation but we can't even pay educators properly to look after the most important members of society. They [these educators] are teachers also (Participant 15).

A small group of pre-service teachers $(n=8)$ also revealed a fear of working with this age range. They stated that they did not have enough practical experience with this age range even after they had completed 10 days of placement with infants and toddlers. The pre-service teachers also commented that they did not have their own children to learn care routines. Their comments often included a statement that they did not have children. For example: 
I don't really have a lot of prior experience to draw upon. I think this age range would really benefit from mothers who have had a lot of experience with care routines. I know what they are about only from a theoretical perspective and a really short practicum of ten days (Participant 3).

The findings from the survey highlight that even though the participants had undertaken 10 days of professional experience, they did not feel adequately prepared to work with infants and toddlers. Although the teacher education program had embedded learning about infants and toddlers across subjects, it appeared not to have been effective for student learning.

\section{Discussion}

The findings from this study raise questions about the adequacy of initial teacher education for employment in settings for children birth to three years. Even though pre-service teachers were qualified in birth to eight years, the majority stated they had only partial knowledge of this younger age range, thus providing another barrier to work with infants and toddlers. Even after a 10-day practicum placement, some pre-service teachers were not confident about care routines and were worried about the responsibility of very young children. This raises questions about the length of the professional practice experience (for instance, is 10 days enough considering other professional experience placements with older children are longer?) and the content within the practicum (what learning actually occurs for the pre-service teachers?). Questions are also raised about program content regarding children within early childhood specialisations. Indeed it may be that within the Bachelor of Primary Education, there was a greater focus on children aged three years and up, at the expense of expertise with children from birth to three years. A discussion may be needed within the early childhood teacher education community about placements with infants and toddlers and program content, as well as the appropriateness of Bachelor of Primary Education degrees with early childhood specialisations. The findings also raise the question of what defines a quality placement. Thorpe et al. (2011) found that a positive placement can lead to positive beliefs about working in the childcare sector.

The questions raised about program content and the length of the birth to three years practicum within early childhood teacher education programs is consistent with the recent Australian study by Garvis and colleagues (2013). They found limited time and assessment tasks focusing on children aged birth to three years. In this study, it would appear that the pre-service teachers in the primary program with an early childhood specialisation did not perceive they had suitable knowledge for this age range. It would be interesting to explore if similar findings exist in other early childhood specialisations that do and do not have a primary school component. It may be that primary education programs generalise ECE to the extent where graduates have no intention of working with young children.

Perhaps consideration needs to be given to specific subjects that focus on infants and toddlers to provide detailed and direct learning about this age range. Within the program in focus, the approach of embedding learning about infants and toddlers across subjects did not appear to be effective in enhancing student knowledge, competence and confidence when working with this age range. According to Garvis et al. (2013), the approach of embedding knowledge about infants and toddlers across subjects, rather than having an individual subject focused on infants and toddlers, appears common across early childhood bachelor degrees. It is important that universities monitor student learning to support confidence when working with infants and toddlers. It may be useful for ACECQA to revise current requirements for infants and toddlers in their teacher education guidelines. It might also be useful to recommend that universities have teaching academics who have experience working with infants and toddlers.

It would be interesting to know where effective infant and toddler teacher education is occurring within Australia that allows graduates to feel confident and competent. Given the variation in approaches across the states and territories in Australia in regard to the delivery of content relevant to infants and toddlers and the time devoted to placements with them (beyond the minimum requirements of 10 days), examples of success would be useful. This would be particularly helpful for early childhood teacher education programs or specialisations that prepare graduands for work with children aged birth to eight years.

Findings from this study however, reveal there are perceived hurdles to early childhood teachers wanting to work with very young children, one being pay and conditions when compared to a teacher working in a school. If we accept the underpinning assumptions about quality enhancement through this mechanismunless these hurdles are addressed and given adequate attention by employers and policy-makers-the planned improved quality in the early childhood sector cannot be realised. Policy-makers must be aware that while policy is mandated, pay also acts as a potential enabler or barrier for professional work. Without comparable conditions of wages for graduates from the same four-year teacher education program, the early childhood sector will not be able to attract the best in the field. These findings align with recent research by Nolan and Rouse (2013) who reported that some of their early childhood teachers preferred to work with older rather than younger children because of perceived better working conditions and levels of respect.

The pre-service teachers in the present study spoke about the status of early childhood teachers in long day care settings being lower than that of primary school teachers. Similar findings have already been highlighted in the Australian literature (Ali, 2009; Ireland, 2006; Sumsion, 
2007). In this study, the pre-service teachers suggested that while the terms 'teacher' and 'educator' were used in teacher education and early childhood placements, the current community did not share the same terminology. Sumsion (2007) describes teachers working in long day child care as not being perceived to be 'real' teachers. It is the role of the early childhood sector as well as government policy-makers to help transform community perceptions of educators and teachers working in the early childhood sector. As Ledoux, Yoder, Hanes and McHenry (2008) note, the early childhood field itself seems unclear about the teacher's role in infant and toddler programs. What is needed is an alignment about the understanding of the role of the teacher with very young children, followed by education of the wider community regarding that role. By explaining the role and importance of a qualified early childhood teacher with the community, a shared understanding and appreciation of the important work teachers do in improving children's outcomes can be developed.

This study is limited in that the early childhood pre-service teacher beliefs were only examined once in this study. Their perceptions may have changed since their initial participation in the survey following graduation. Longitudinal studies are needed to track early childhood teachers as they enter the field. A longitudinal study would also benefit from not only examining multi-time measurements but also multimethod approaches that include quantitative and qualitative data. More research is also needed within early childhood teacher education on how to effectively allow pre-service early childhood students to become competent to work with infants and toddlers.

\section{Conclusion}

This study has provided a small snapshot into the perceptions of 25 pre-service early childhood specialisation graduand teachers who were about to graduate and enter the field. The study has shown that despite learning about infants and toddlers in their teacher education and having a 10-day placement with infants and toddlers, graduating teachers still did not feel confident or competent overall. Other barriers to working with young children included pay levels and the lack of respect for working with young children. Interestingly, pre-service teachers did not mention shift work and long hours as barriers.

If we are committed to the youngest of children in care in Australia, the profession, universities and policy-makers must work together to advocate quality of education and care for infants and toddlers. While quality of education and care had been a focus in kindergarten, it is now time to focus on all children in early childhood settings, including infants and toddlers. This process may start with the identification of infants and toddlers as a specialist area of ECE in research, pedagogy, curriculum and policy. It is recommended that a revision of current ACECQA guidelines for teacher education are considered, as well as universities staffing early childhood education programs with teacher educators who have experience working with infants and toddlers. Part of this recommendation also includes the differences between a primary degree with an early childhood specialisation and an early childhood degree. This study shows graduates from a primary degree do not appear interested in working with infants and toddlers. Further research is needed on pre-service teacher perceptions between the two types of programs. Findings from further studies would inform the design of programs and be highly relevant to filling the current need for early childhood teachers in long day care. Not only will this lead to improved quality, it will also raise the profile of infants and toddlers. It is through stronger advocacy for infants and toddlers that we can enhance the quality of care for all children in early childhood settings.

\section{References}

Ali, C. (2009). Impacts on the professional practice of kindergarten teachers working in long day care (Unpublished honours thesis). Deakin University, Victoria, Australia.

Cohen, L., Manion, L., \& Morrison, K. (2000). Research methods in education. London, UK and New York, NY: Routledge Falmer.

Council of Australian Governments (COAG). (2009). National Quality Framework for Early Childhood Education and Care. Retrieved 3 December, 2013, from www.coag.gov.au/early_childhood.

de Leon-Carillo, C. M. (2007). Prospective teacher's pre- and postpracticum beliefs on teaching. KEDI Journal of Educational Policy, 4(1), 25-40.

Dowling, A., \& O'Malley, K. (2009). Preschool education in Australia. Melbourne, VIC: Australian Council for Educational Research.

Fink, A. (2003). How to design survey studies (2nd edn). London, UK: Sage Publications.

Garvis, S., Lemon, N., Pendergast, D., \& Yim, B. (2013). A content analysis of early childhood teachers' theoretical and practical experiences with infants and toddlers in Australian teacher education programs. Australian Journal of Teacher Education, 38(9), 1-11. Retrieved 3 December, 2013, from http://dx.doi. org/10.14221/ajte.2013v38n9.5.

Hannon, P. (2003). Developmental neuroscience: Implications for early childhood intervention and education. Current Paediatrics, 13(1), 58-63.

Ireland, L. (2006). When babies have teachers: A study of how three community based children's services employ early childhood teachers in infant-toddler programs. Paper presented at Australian Association for Research in Education (AARE) Conference, University of South Australia.

Krippendorff, K. (2004). Content analysis: An introduction to its methodology. Beverley Hills, CA: Sage.

Ledoux, M. W., Yoder, N., Hanes, B., \& McHenry, N.(2008). Teacher candidate training in high quality day care centres and in lower socioeconomic settings. In P. G. Grotewell \& Y. R. Burton (Eds.), Early childhood education: Issues and developments (pp. 7-22). New York, NY: Nova Science Publishers.

Mitchell, L. (2010). Constructions of childhood in early childhood education policy debate in New Zealand. Contemporary Issues in Early Childhood, 11(4), 328-341. doi: 10.2304/ciec.2010.11.4.328 
Nolan, A., \& Rouse, E. (2013). Where to from here? Career choices of pre-service teachers undertaking a dual early childhood/primary qualification. Australian Journal of Teacher Education, 38(1), 1-10.

Norris, D. J. (2010). Raising the educational requirements for teachers in infant toddler classrooms: Implications for institutions of higher education. Journal of Early Childhood Teacher Education, $31,146-158$.

O'Neill, S., \& Stephenson, J. (2012). Does classroom management coursework influence pre-service teachers' perceived preparedness of confidence? Teaching and Teacher Education, 28, 1131-1143.

Queensland Government Office for Early Childhood Education and Care. (2013). National Quality Framework. Retrieved 2 February, 2015, from http://deta.qld.gov.au/earlychildhood/office/national/ framework.html.

Recchia, S., \& Shin, M. (2010). 'Baby teachers': How preservice early childhood students transform their conceptions of teaching and learning through infant practicum. Early Years, 30(2), 135-145.

Sax, L. J., Gilmartin, S. K., \& Bryant, A. N. (2003). Assessing response rates and nonresponse bias in web and paper surveys. Research in Higher Education, 44, 409-432. doi: 10.1023/A:1024232915870

Schwandt, T. A. (1994). Constructivist, interpretivist approaches to human inquiry. In N. K. Denzin \& Y. S. Lincoln (Eds.), Handbook of qualitative research (pp. 118-137). Thousand Oaks, CA: Sage.

Stough, L. (2006). The place of classroom management in the standards in teacher education. In C. M. Evertson \& C. S. Weinstein (Eds.), Handbook of classroom management. Research, practice, and contemporary issues (pp. 909-924). Mahwah, NJ: Lawrence Erlbaum.

Sumsion, J. (2007). Sustaining the employment of early childhood teachers in long day care: A case for robust hope, critical imagination and critical action. Asia-Pacific Journal of Teacher Education, 35, 311-327.

Sylva, K., Melhuish, E., Sammons, P., Siraj-Blatchford, I., \& Taggart, B. (2011). Early childhood matters: Evidence from the effective preschool and primary school education project. London, UK: Routledge.

Thorpe, K., Ailwood, K., Brownlee, J., \& Boyd, W. (2011). Who wants to work in child care? Pre-service early chidlhood teachers' consideration of work in the childcare sector. Australasian Journal of Early Childhood, 36(1), 85-94.

Wallen, N., \& Fraenkel, J. (2001). Educational research: A guide to the process (2nd edn). Mahwah, NJ: Erlbaum. 